Simonsen, D. H. \& van Wagtendonk, W. J. (1956). J. gen. Microbiol. 15, 39-46

\title{
The Succinoxidase System of Killer and Sensitive Stocks of Paramecium aurelia, Variety 4
}

\author{
BY D. H. SIMONSEN* aND W. J. VAN WAGTENDONK \\ Department of Zoology, Indiana University, Bloomington, Indiana, U.S.A.
}

SUMMARY : Different pathways of terminal oxidation exist in killer and sensitive stocks of Paramecium aurelia, variety 4, stock 51.7. The killers contain an active succinoxidase system which is absent, or present only in small concentrations, in the sensitives. The succinoxidase system might therefore either be necessary for the maintenance of the cytoplasmic particle 'kappa' or is intrinsically associated with it.

'Killer' and 'sensitive' phenotypes of Paramecium aurelia, variety 4, occur within stock 51.7 of this organism (Sonneborn, 1947). The two types are identical with respect to the nuclear genotype, but differ by the presence of the cytoplasmic factor, 'kappa', in the killers. The presence of kappa results in an altered respiratory metabolism in the killer cell (Simonsen \& van Wagtendonk, $1949,1952)$. The respiratory rate of the killer cells is almost double that of the sensitives. The lack of respiratory inhibition in the killers by concentrations of sodium azide, which are strongly inhibitory to respiration in the sensitives as well as the observed low cytochrome oxidase activity, led to the conclusion that the extra respiratory capacity of the killers was not attributable to a cytochrome type respiration. These studies indicated that some basic difference must exist in the terminal respiratory pathways of the two stocks. This must be due to the presence of kappa in the killer cell. Killer and sensitive stocks also differ in their nutritional requirements. An axenic medium which will support the growth of sensitive paramecia will not support the growth of killers (van Wagtendonk, Conner, Miller \& Rao, 1953). Further attempts to determine the function of kappa in the metabolism of the killer organisms are described in this communication.

\section{METHODS}

The stocks of Paramecium aurelia. Sensitive and killer cultures of Paramecium aurelia, variety 4 , stock 51.7 were used. The cultures were grown at $27^{\circ}$ according to methods previously described for large mass cultures (Simonsen \& van Wagtendonk, 1952).

Preparation of the homogenates. Approximately $6 \mathrm{l}$. of the culture which had been fed with Aerobacter aerogenes $48 \mathrm{hr}$. previously were concentrated to a volume of $20 \mathrm{ml}$. by filtration on a Berkefeld filter. This concentrated suspension of paramecia was then transferred to an electromigration apparatus in order to effect a further concentration and washing of the cells (van Wagtendonk, Simonsen \& Zill, 1952). A modified migration medium was made up as follows : $200 \mathrm{mg}$. $\mathrm{NaCl} ; 50 \mathrm{mg}$. $\mathrm{KCl} ; 100 \mathrm{mg} \cdot \mathrm{CaCl}_{2} \cdot \mathrm{H}_{2} \mathrm{O} ; 50 \mathrm{mg} \cdot \mathrm{MgSO}_{4} \cdot 7 \mathrm{H}_{2} \mathrm{O}$;

\footnotetext{
* Present address : Research Laboratories, The Upjohn Co., Kalamazoo, Michigan, U.S.A.
} 
$25 \mathrm{mg} . \mathrm{K}_{2} \mathrm{HPO}_{4} ; 25 \mathrm{mg}$. $\mathrm{KH}_{2} \mathrm{PO}_{4}$, dissolved in 1 l. glass-redistilled water. The concentrated suspension of paramecia (8-10 ml.) was withdrawn from the apparatus and transferred to a $10 \mathrm{ml}$. graduated conical centrifuge tube. The total number of paramecia was determined by diluting measured samples of the suspension to appropriate volumes and counting the number of organisms present directly. At least three determinations were made on each suspension. The suspension was then centrifuged at 1500 r.p.m. in a refrigerated centrifuge, the supernatant fluid poured off without special precautions, and the loss in centrifugation determined by a direct count of the organisms present in the supernatant fluid. The organisms were resuspended in the desired respiration medium and the concentration was adjusted to about 500,000 organisms $/ \mathrm{ml}$. This suspension was then transferred to a tight-fitting Potter-Elvehjem glass homogenizer powered by a laboratory stirring motor. Each sample was homogenized for $4 \mathrm{~min}$. and then examined for the presence of whole organisms, which were removed with a micropipette. All operations involved in the preparation of the homogenates were carried out in a cold room at $4^{\circ}$, and all solutions and glassware were chilled before use.

Media used for homogenization. Three different media were used in preparing the homogenates. In one series of experiments the saline phosphate solution used for the electromigration of the paramecia was used. In another series distilled water was added to the packed organisms before homogenization. In a third series, sodium phosphate buffer ( $\mathrm{pH} \mathrm{7 \cdot 2)}$ was added so that the final concentration of phosphate was $0.05 \mathrm{M}$. The $\mathrm{pH}$ value of all solutions was maintained at $7 \cdot \mathbf{1}-\mathbf{7} \cdot \mathbf{2}$.

Respiration measurements. The Cartesian diver technique was used for these determinations (Simonsen \& van Wagtendonk, 1952). The main drop contained homogenate equivalent to 1500-1800 paramecia. It was determined that a linear endogenous respiratory response proportional to the numbers of organisms used could be obtained when the equivalent of 1000-5000 paramecia were used for each diver vessel. Inhibitors and substrates were added according to the needs of the particular experiment by the side-drop technique. Following a $\mathbf{3 0}$ min. equilibration period, the side drops were added to the homogenates and readings were made at $10 \mathrm{~min}$. intervals for 60 or $90 \mathrm{~min}$. thereafter. Each experiment was repeated from three to five times with appropriate controls. The tables represent a composite of the results obtained. There was little variation in the relative rates measured in duplicate experiments.

Substrates and inhibitors. Sodium succinate alone, or in combination with other substances, was added to the homogenates to a final concentration of 0.05 M. Methylene blue was used at a concentration of $5 \times 10^{-4} \mathrm{M}$. Following the suggestions of Schneider \& Potter (1943), Swingle, Axelrod \& Elvehjem (1942) and Keilin \& Hartree (1949), aluminium chloride and calcium chloride were incorporated in the medium at a final concentration of $10^{-4} \mathrm{M}$. Sodium malonate, $0.08 \mathrm{M}$, was used as a specific inhibitor of the succinic dehydrogenase system. The concentrations of all of these solutions before addition to the homogenate were ten times the final concentrations reported above. The $\mathrm{pH}$ value was adjusted to $\mathbf{7 \cdot 2}$. 


\section{RESULTS}

\section{Influence of homogenization media upon endogenous respiratory rates}

The measured succinoxidase activity of tissue homogenates is dependent upon the method of preparation of the homogenates (Keilin \& Hartree, 1949). Factors which influence the activity include salt concentration, nature of the buffer system used, and the concentration of phosphate in the medium. Most of the effects observed were attributable to changes in the colloidal nature of the enzyme complexes comprising the particular preparation.

Homogenates of killers and sensitives prepared in the migration medium were compared with respect to their endogenous respiratory rates. It was found that the rate for the killer preparation was $11.5 \times 10^{-6} \mu \mathrm{l}$./organism/hr. compared with $5.5 \times 10^{-6} \mu \mathrm{l}$./organism/hr. for the sensitives (Table 1). These results confirm the earlier observations made with intact organisms, that the killers have a respiration rate double that of the sensitives.

Table 1. Influence of medium on oxygen consumption of homogenates of killer and sensitive paramecia

\begin{tabular}{|c|c|c|c|c|}
\hline \multirow[b]{2}{*}{ Medium } & \multicolumn{2}{|c|}{ Sensitive } & \multicolumn{2}{|c|}{ Killer } \\
\hline & $q_{\mathrm{O}_{2}}{ }^{*}$ & $\Delta q_{0_{2}} \dagger$ & $g_{\mathrm{O}_{2}}$ & $\Delta q_{\mathrm{o}_{\mathrm{a}}}$ \\
\hline $\begin{array}{l}\text { Saline solution } \\
\quad+\text { succinate }(0.05 \mathrm{M})\end{array}$ & $\begin{array}{l}5 \cdot 5 \\
6 \cdot 0\end{array}$ & $\overline{0.5}$ & $\begin{array}{l}11 \cdot 5 \\
12 \cdot 8\end{array}$ & $\overrightarrow{1 \cdot 3}$ \\
\hline $\begin{array}{l}\text { Distilled water } \\
\quad+\text { succinate }(0.05 \mathrm{~m})\end{array}$ & $\begin{array}{l}2 \cdot 8 \\
\mathbf{3 \cdot 4}\end{array}$ & $\overline{0 \cdot 6}$ & $\begin{array}{r}11 \cdot 8 \\
6 \cdot 0\end{array}$ & $-5 \cdot 8$ \\
\hline $\begin{array}{l}\text { Phosphate }(0.05 \mathrm{M}) \\
\quad \text { + succinate }(0.05 \mathrm{M})\end{array}$ & $\begin{array}{l}0 \cdot 4 \\
0.7\end{array}$ & $\overline{0 \cdot 3}$ & $\begin{array}{l}11 \cdot 7 \\
26 \cdot 5\end{array}$ & $\overline{14 \cdot 8}$ \\
\hline
\end{tabular}

* The $q_{\mathrm{o}_{\mathrm{g}}}$ is expressed as $\mu \mathrm{l}$. $\times 10^{-6}$ of oxygen consumed/cell-hour.

$\dagger$ The $\Delta q_{\mathrm{o}}$, represents the difference between the endogenous rate and that measured with added substrate.

The figures in the table represent the average of four separate experiments with a $\pm 10 \%$ deviation from the mean.

When distilled water or phosphate buffer $(0.05 \mathrm{M})$ were used, the endogenous $q_{\mathrm{o}_{2}}\left(\mu \mathrm{l} . \mathrm{O}_{2}\right.$ consumed/organism/hr.) of the homogenate of killer organisms remained at the same high level (about $12 \times 10^{-6} \mu \mathrm{l}$./organism/hr.) (Table 1). By contrast, the homogenate of sensitive organisms exhibited a lowered $q_{\mathrm{o}_{2}}$ when distilled water was used (about $2.8 \times 10^{-6} \mu \mathrm{l}$./organism/hr.). When phosphate buffer was used the $q_{o_{2}}$ was diminished to a value which was below the sensitivity of the measuring apparatus. From these results it may be concluded that the endogenous respiration of the killer homogenates is independent of the method of preparation, whereas that of the sensitives is strictly dependent.

Influence of added succinate. The addition of succinate $(0.05 \mathrm{M})$ to homogenates of sensitive organisms prepared in any of the three media caused only a slight stimulation of the endogenous $q_{\mathrm{O}_{2}}$. With the killer preparations, however, the effects of added succinate were pronounced and dependent upon the media used for homogenization. When saline solution was used, there was a slight stimulation of the $q_{\mathrm{o}}$, by added succinate which was comparable to 
that found with sensitive organisms prepared in the same medium (Table 1). Distilled water preparations of killer organisms responded to the addition of succinate with a marked inhibition in respiration (Table 1). Finally, in the phosphate buffer medium, the added succinate caused a doubling of the respiratory rate of the killer preparation (Table 1). These data provide evidence for the presence of a succinoxidase system in the killers which is dependent upon the presence of phosphate in the homogenization medium. In other succinoxidase systems, increased activity in the presence of phosphate has been noted (Keilin \& Hartree, 1949; Ball \& Cooper, 1949; Slater, 1949; Bonner, 1954). It was concluded that this effect was due to the colloidal state of the preparations as influenced by phosphate. Esterification of inorganic phosphate was demonstrated when succinate was oxidized either aerobically or anaerobically by cell-free extracts of Escherichia coli (Hersey \& Ajl, $1951 a, b)$. Also it has been shown that phosphate utilization is dependent upon the electron acceptor system present (Kearny, Singer \& Zastrow 1955). Thus, phosphate may act in the killer preparation by influencing the colloidal nature of the succinoxidase system. Since there was only little stimulation by added succinate in the homogenates of sensitive organisms and since there was no stimulation in the presence of phosphate, it may be concluded that succinoxidase is absent, or has a different activity in the sensitive system. The magnitude of the differences between killer and sensitive organisms when phosphate buffer was used made this the medium of choice for further experiments on the succinoxidase system.

Effects of the addition of methylene blue $(0 \cdot 0005 \mathrm{M})$. Further, to characterize the activity of succinate, methylene blue was added to homogenates prepared in phosphate buffer. Methylene blue in the presence of calcium and aluminium ions, but without added succinate, caused a marked stimulation of the respiration of both killer and sensitive homogenates (Table 2). The increase was of the same order of magnitude in both preparations, $7 \cdot 8 \times 10^{-6} \mu \mathrm{l}$./organism/hr. for the killers and $8.8 \times 10^{-6}$ for the sensitives. This stimulation of the endogenous metabolism by methylene blue indicated the presence of some system common to both killers and sensitives and independent of the presence or absence of kappa. Further, the presence of malonate $(0.08 \mathrm{M})$ did not influence this methylene blue catalysed oxidation process (Table 3 ). Therefore this stimulation cannot be due to Krebs-cycle activity and must be due to the oxidation of some substrate present in high concentration in both cell types. These results may be contrasted to those found with Paramecium caudatum in which the addition of methylene blue to homogenates resulted in no increase in the endogenous respiratory rate (Humphrey \& Humphrey, 1947, 1948).

Effect of succinate in the presence of methylene blue. The addition of succinate to the homogenates of sensitives stimulated by methylene blue caused only a slight additional increase in the $q_{\mathrm{o}}$ (Table 2). With the homogenates of killers, the addition of succinate with methylene blue stimulated the oxygen consumption to a $q_{\mathrm{o}_{2}}$ of $24.5 \times 10^{-6} \mu \mathrm{l}$./organism/hr. The actual increase caused by the addition of succinate in this system was comparable to the increase over the endogenous rate produced by succinate in the absence of methylene blue. 
Evidence for the presence of succinic dehydrogenase in other species of paramecia as well as in other ciliated protozoa has been compiled. The early work of Leichsenring (1925) demonstrated that the addition of succinate to $P$ aramecium caudatum resulted in a stimulation of respiration of between 8 and $9 \%$. Humphrey \& Humphrey $(1947,1948)$, using homogenates of $P$. caudatum, noted an increase over the endogenous respiration of $125 \%$ in the presence of succinate which could be reversed by the addition of malonate. Later work (Holland \& Humphrey, 1953 $a, b$; van Gremsbergen \& Reynaerts-de Pont, 1952) with intact $P$. caudatum confirmed the results of Leichsenring. Seaman $(1949,1950,1951,1952)$ compiled evidence for the existence of the Krebs cycle in Tetrahymena pyriformis $(S)$; but with $T$. pyriformis $(G L)$, Ryley (1952) found no evidence for the oxidation of succinate in the presence or absence of added cytochrome $c$, although an active dehydrogenase was demonstrated by the Thunberg technique.

In all of the work cited, the magnitude of the succinic dehydrogenase or oxidase activity was slight compared with the activities in mammalian tissues; this has led to the suggestion that this system may be relatively unimportant to the economy of the paramecia when compared to other pathways (Holland \& Humphrey, 1953b).

In the case of stock 51.7 of Paramecium aurelia, the genetic transformation from killer to sensitive, in so far as can be determined, involves only the loss of kappa particles. This loss, however, results in the elimination of the ability to oxidize succinate. Under the cultural conditions used, the sensitive organisms grow at the same rate as the killers. From this it may be concluded that succinoxidase is either necessary for the maintenance of the kappa particles or is intrinsically associated with them. When kappa is eliminated, i.e. in the sensitives, succinoxidase is no longer important to the economy of the organism.

An analogy may be made between this system and the acriflavine-induced 'small colony' mutants in the yeast Saccharomyces cerevisiae (Ephrussi, l'Heritier \& Hottingeur, 1949; Slonimski \& Ephrussi, 1949 ; Ephrussi \& Hottingeur, 1951). The induction of 'small colony' mutants involves the loss of a cytoplasmic particle necessary for the synthesis of cytochrome oxidase and succinoxidase. Hirsch (1952) has established that this transformation involves a modification in the enzymic make-up of the organism with the loss of the enzymes cytochrome oxidase, succinic dehydrogenase, $\alpha$-glycerophosphate dehydrogenase, and a DPN-cytochrome $c$ reductase, all of which are linked to the particulate component of normal yeast.

In Paramecium aurelia the loss of kappa results in the loss of succinoxidase as well as some complex of enzymes which contribute to the high endogenous metabolism of the killers. The demonstration of a higher cytochrome oxidase activity in the sensitives, determined by the method of Smith \& Stotz (1949), would prevent a strict analogy. The close association of succinoxidase and cytochrome oxidase as found in many systems is not obligatory for all organisms. In the filarial parasites there is ample evidence for the presence of succinic dehydrogenase activity in association with a particulate fraction, 
Therefore the succinic dehydrogenase activity of the killers is independent of the presence or absence of methylene blue.

The effect of malonate. Malonate when added to homogenates of killers as well as sensitives in the presence or absence of methylene blue had little effect upon the respiratory rates (Table 3). However, when malonate was added to the killer homogenate in the presence of succinate, the stimulation which had been noted with succinate was almost completely abolished. The use of malonate as a competitive inhibitor of succinate oxidation demonstrates the true nature of the succinoxidase activity which was measured in the killer homogenates.

Table 2. Metabolism of succinate in the presence and absence of methylene blue

$\quad$ Substrate
Endogenous (phosphate, $0.05 \mathrm{M})$
Methylene blue
Succinate $(0.05 \mathrm{M})$
Methylene blue + succinate $(0.05 \mathrm{M})$

\begin{tabular}{|c|c|}
\hline \multicolumn{2}{|c|}{ Sensitive } \\
\hline$q_{\mathrm{o}}{ }^{*}$ & $\Delta q_{\mathrm{o}_{2}} \dagger$ \\
\hline 0.5 & - \\
\hline $9 \cdot 3$ & $8 \cdot 8$ \\
\hline 0.8 & 0.3 \\
\hline $10 \cdot 5$ & $10 \cdot 0$ \\
\hline
\end{tabular}

\begin{tabular}{|c|c|}
\hline \multicolumn{2}{|c|}{ Killer } \\
\hline$q_{o_{2}}$ & $\Delta q_{o}$ \\
\hline 11.7 & - \\
\hline $10 \cdot 0$ & $7 \cdot 3$ \\
\hline 24.5 & $12 \cdot 8$ \\
\hline $31 \cdot 0$ & $19 \cdot 8$ \\
\hline
\end{tabular}

- The $q_{\mathrm{o}_{2}}$ is expressed as $\mu \mathrm{l}$. $\times 10^{-6}$ of oxygen consumed/cell-hour.

† The $\Delta q_{\mathrm{o}_{2}}$ represents the difference between the endogenous rate and that measured with added substrate.

The figures in the table represent the average of four experiments with a $\pm 10 \%$ deviation from the mean.

Table 3. Influence of added malonate on the succinate stimulated respiration

\begin{tabular}{|c|c|c|c|c|}
\hline \multirow[b]{2}{*}{ Substrate } & \multicolumn{2}{|c|}{ Sensitive } & \multicolumn{2}{|c|}{ Killer } \\
\hline & $q_{\mathrm{o}_{1}} *$ & $\Delta q_{0_{2}} t$ & $q_{\mathrm{O}_{2}}$ & $\Delta q_{O_{2}}$ \\
\hline Endogenous (phosphate, $0.05 \mathrm{M}$ ) & 1.0 & - & $11 \cdot 2$ & - \\
\hline Methylene blue & $10 \cdot 8$ & $\mathbf{9} \cdot \mathbf{3}$ & $10 \cdot 2$ & $8 \cdot 0$ \\
\hline Methylene blue + succinate $(0.05 \mathrm{~m})$ & $11 \cdot 7$ & $10 \cdot 7$ & $\mathbf{8 3 \cdot 2}$ & $\mathbf{2 2 \cdot 0}$ \\
\hline Methylene blue + malonate $(0.08 \mathrm{~m})$ & $10 \cdot 7$ & $9 \cdot 7$ & $17 \cdot 2$ & $6 \cdot 0$ \\
\hline $\begin{array}{l}\text { Methylene blue + succinate } \\
(0-05 \mathrm{M}) \text { + malonate }(0.08 \mathrm{M})\end{array}$ & $10 \cdot 9$ & $9 \cdot 0$ & $\mathbf{2 1} \cdot \mathbf{0}$ & $9 \cdot 8$ \\
\hline
\end{tabular}

\section{DISCUSSION}

The results of the present study provide further evidence for the existence of different pathways of terminal oxidation as between killer and sensitive stocks of Paramecium aurelia, variety 4, stock 51.7. The demonstration of an active succinoxidase system in the killers which is absent, or present in only low concentration, in the sensitives indicates that the kappa particles possess a metabolic function in the cell. An additional difference between the two types has been established with regard to the endogenous metabolism of cell homogenates. 
while there is no evidence for the presence of cytochrome oxidase activity (Bueding, 1949; Bueding \& Charms, 1951; Ross \& Bueding, 1950).

The hypothesis that the enzymic activities of succinoxidase and other enzymes which catalyse terminal oxidative processes are associated directly with kappa particles, is attractive. However, Preer \& Stark (1953) with purified preparations of kappa particles were unable to demonstrate any enzymic activity in their preparation, but they recognized the limitations of the histochemical techniques used. If these enzymes are not an intrinsic part of the kappa particle, then they must be necessary for the production of energy for the maintenance and reproduction of the kappa particle and the synthesis of the killer substance, paramecin.

One of us, D. H. Simonsen, was a post-doctoral research fellow of the National Cancer Institute of the National Institutes of Health, 1951-2. Part of this work was carried out under a contract between the Office of Naval Research and Indiana University (no. 6 onr-18010). Supported by a research grant (no. C-2160 (C2)-) from the National Institutes of Health and by grants from the Rockefeller Foundation and Indiana University.

\section{REFERENCES}

Ball, E. G. \& Cooper, D. (1949). The activity of succinate oxidase in relation to phosphate and phosphorus compounds. J. biol. Chem. 180, 113.

Bonver, W. D. (1954). Activation of the succinic dehydrogenase-cytochrome system. Biochem. J. 56, 274.

BUEDrNG, E. (1949). Studies on the metabolism of the filarial worm Litomosoides carinii. J, exp. Med. 89, 107-130.

Bueding, E. \& Chanms, B. (1951). Respiratory metabolism of parasitic helminths without participation of the cytochrome system. Nature, Lond. 167, 149.

Ephrussi, B., L'Heritier, P. \& Hottingeur, H. (1949). Action de l'acriflavine sur les levures. VI. Analyse quantitative de la transformation des populations. Ann. Inst. Pasteur, 77, 64.

Ephrussi, B. \& Hottingeur, H. (1951). On an unstable cell state in yeast. Cold Spr. Harb. Symp. quant. Biol. 16, 75.

Gremsbergen, G. van \& Reynaerts-de Pont, F. (1952). Respiratorisch metabolisme van Paramecium caudatum. Natuurwet. Tijdschr. 34, 31.

Hersey, D. F. \& AJL, S. J. (1951 a). Adinosinetriphosphate formation in the oxidation of succinic acid by bacteria. J. biol. Chem. 191, 113.

Hersey, D. F. \& AJL, S. J. (1951 b). Phosphorylation due to oxidation of succinic acid by cell-free extracts of Escherichia coli. J. gen. Physiol. 34, 295.

Hirsch, H. M. (1952). A comparative study of aconitase, fumarase, and DPN-linked isocitric dehydrogenase in normal and respiration-deficient yeast. Biochim. biophys. Acta, 9, 674 .

Holland, J. \& Humphrey, G. F. (1953a). The metabolism of Paramecium caudatum. I. Respiration. Aust. J. exp. Biol. med. Sci. 31, 292.

Holland, J. \& Humphrey, G. F. (1953b). The metabolism of Paramecium caudatum. II. The effect of respiratory inhibitors. Aust. J. exp. Biol. med. Sci. 31, 299.

Humphrey, B. A. \& Humphrey, G. F. (1947). Succinic dehydrogenase in protozoa. Nature, Lond. 159, 374.

Humphrey, B. A. \& Humphrey, G. F. (1948). Studies in the respiration of Paramecium caudatum. J. exp. Biol. 25, 123.

Kearny, E. B., Singer, T. P. \& Zastrow, N. (1955). On the requirement of succinic dehydrogenase for inorganic phosphate. Arch. Biochem. Biophys. 55, 579. 
Keilin, D. \& Hartree, E. F. (1949). Activity of the succinic dehydrogenasecytochrome system in different tissue preparations. Biochem. J. 44, 205.

LEICHSENRING, J. (1925). Factors influencing the rate of oxygen consumption in unicellular organisms. Amer. J. Physiol. 75, 84.

Preer, J. R. Jun. \& Stark, P. (1953). Cytological observations on the cytoplasmic factor 'Kappa' in Paramecium aurelia. Exp. Cell Res. 5, 478.

Ross, O. A. \& Bueding, E. (1950). Survival of Schistosoma mansoni in vitro. Proc. Soc. exp. Biol., N.Y. 73, 179.

RYLEY, J. F. (1952). Studies on the metabolism of the protozoa. 3. Metabolism of the ciliate Tetrahymena pyriformis (Glaucoma pyriformis). Biochem. J. 52, 483.

Schneider, W. C.\& Potter, V. R. (1943). The assay of animal tissues for respiratory enzymes. II. Succinic dehydrogenase and cytochrome oxidase. J. biol. Chem. $149,217$.

Staman, G. R. (1949). The presence of the tricarboxylic acid cycle in the ciliate, Colpidium campylum. Biol. Bull., Woods Hole, 96, 257.

Seaman, G. R. (1950). Utilization of acetate by Tetrahymenageleii (S). J.biol. Chem. 186, 97 .

Seaman, G. R. (1951). Enzyme systems in Tetrahymena geleii $(S)$. I. Anaerobic dehydrogenases concerned with carbohydrate oxidation. J. gen. Physiol. 34, 775.

SEaman, G. R. (1952). Enzyme systems in Tetrahymena geleii (S). IV. Combination of arsenoacetate with carbonyl affinity points on the succinic dehydrogenase. Arch. Biochem. Biophys. 35, 132.

Simonsen, D. H. \& Wagtendonk, W. J. van (1949). Oxygen consumption of 'killer' and 'sensitive' stocks of Paramecium aurelia. Fed. Proc. 8, 250.

Simonsen, D. H. \& Wagtendonk, W. J. van (1952). Respiratory studies on Paramecium aurelia, variety 4, killers and sensitives. Biochim. biophys. Acta, 9, 515.

Si.ATER, E. C. (1949). Action of inhibitors on the system of enzymes which catalyze the aerobic oxidation of succinate. Biochem. J. 45, 8 .

Slonimsir, P. \& Ephrussi, B. (1949). Action de l'acriflavine sur les levures. V. Le système des cytochromes des mutants 'petite colonie'. Ann. Inst. Pasteur, 77, 47 .

Smith, F. G. \& Stotz, F. (1949). A colorimetric method for the determination of phenol oxidase in plant material. $J$. biol. Chem. 179, 865.

Sonnebonn, T. M. (1947). Recent advances in the genetics of Paramecium and Euplotes. Advanc. Genet. 1, 263.

Swingle, K. F., Axelrod, A. E. \& Elvehuem, C. A. (1942). Studies on the succinoxidase of rat liver in riboflavin deficiency. J. biol. Chem. 145, 297.

Wagtendonk, W. J. van, Conner, R. L., Miller, C. A. \& Rao, M. R. R. (1953). Growth requirements of Paramecium aurelia, var, 4, stock 51.7, sensitives and killers, in axenic medium. Ann. N.Y. Acad. Sci. 56, 929.

Wagtendonk, W. J. van, Simonsen, D. H. \& Zill, L. P. (1952). The use of electromigration techniques in washing and concentrating cultures of Paramecium aurelia. Physiol. Zoöl. 25, 312. 